\title{
RESTAURAÇÃO DA ESTRUTURA DO SOLO POR SEQUÊNCIAS CULTURAIS IMPLANTADAS EM SEMEADURA DIRETA, E SUA RELAÇÃO COM A EROSÃO HÍDRICA EM DISTINTAS CONDIÇÕES FÍSICAS DE SUPERFÍCIE ${ }^{(1)}$
}

\author{
Jeane Cruz Portela ${ }^{(2)}$, Neroli Pedro Cogo ${ }^{(3)}$, Tatiane Bagatini ${ }^{(4)}$, Juliana Prado \\ Chagas $^{(4)} \&$ Gustavo Portz ${ }^{(4)}$
}

\begin{abstract}
RESUMO
A estrutura do solo desempenha papel de destaque no crescimento de plantas e no controle da erosão e, por conseguinte, na produção de alimentos e na conservação do solo e da água. Considerando isso, realizou-se este trabalho com o objetivo de implementar e acompanhar o processo de restauração da estrutura de um solo degradado, por meio de sequências culturais (gramíneas e leguminosas de inverno e verão, dispostas nos modos de cultivo isolado e consorciado), implantadas em semeadura direta, e posteriormente verificar sua relação com as perdas de solo e água causadas pela erosão hídrica pluvial, em distintas condições físicas de superfície (solo não mobilizado, com e sem crosta; solo recém-mobilizado, por meio de escarificação e de escarificação seguida-um mês mais tarde-de gradagem; e coberturas por resíduo cultural de 100, 18 e $0 \%$ ). O estudo foi desenvolvido em campo, com chuva simulada, na EEA/UFRGS, em Eldorado do Sul (RS), de maio de 2004 a dezembro de 2007. Os testes de erosão, em número de seis e espaçados um do outro ao redor de uma semana, foram realizados de outubro a dezembro de 2007. Utilizou-se um Argissolo Vermelho distrófico típico com textura francoargiloarenosa na camada superficial e declividade média de $0,115 \mathrm{~m} \mathrm{~m}^{-1}$, em avançado grau de degradação. As chuvas simuladas, na intensidade constante de $64 \mathrm{~mm} \mathrm{~h}^{-1}$ e com duração variando de 1 a $3 \mathrm{~h}$, foram aplicadas com o aparelho simulador de braços rotativos, sendo os resultados de perda de solo e água ajustados para a duração única de chuva de 1,5 h. Foram medidos atributos de solo e planta
\end{abstract}

(1) Parte da Tese de Doutorado do primeiro autor apresentada ao Programa de Pós-Graduação em Ciência do Solo da Universidade Federal do Rio Grande do Sul - UFRGS, realizada com recursos financeiros do Auxílio "grant" e da Taxa de Bancada do CNPq. Trabalho apresentado no XXXII Congresso Brasileiro de Ciência do solo - CBCS/SBCS, Fortaleza (CE), 2009. Recebido para publicação em setembro de 2009 e aprovado em maio de 2010.

(2) Doutora em Ciência do Solo, PPGCS, Universidade Federal do Rio Grande do Sul - UFRGS. Av. Bento Gonçalves 7712 , CEP 91540-000 Porto Alegre (RS). E-mail: jeanecportela@yahoo.com.br

(3) Professor Associado II, Departamento de Solos, Faculdade de Agronomia, UFRGS. Bolsista do CNPq. E-mail: neroli@ufrgs.br

(4) Ex-Acadêmicos da Faculdade de Agronomia, UFRGS, Ex-bolsistas de iniciação cientifica do CNPq, PIBIC-CNPq/UFRGS e FAPERGS. E-mails: respectivamente: tatibagatini@yahoo.com.br; juju_ptn@yahoo.com.br e gportz@gmail.com 
nas parcelas experimentais e de erosão hídrica no escoamento superficial. As sequências culturais e os testes de erosão influenciaram significativamente os resultados da pesquisa, com as diferenças sendo maiores nos últimos e com as condições físicas externas ou superficiais do solo influenciando o processo erosivo mais do que as condições físicas internas ou subsuperficiais. De modo geral, todas as sequências culturais foram eficazes na restauração da estrutura do solo no período da experimentação: aquela que envolveu teosinto no que se refere à perda de solo e água e a que envolveu milho + feijão-miúdo e milheto no tocante à perda de solo foram as que melhor controlaram o processo de erosão hídrica pluvial. A superfície de solo não mobilizada e com pouca cobertura por resíduo cultural foi a que mais favoreceu a enxurrada e a erosão, independentemente da presença e do tipo de crosta, especialmente quando esta última foi levemente rompida antes da aplicação da chuva. A superfície de solo inteiramente coberta por resíduo cultural - tenha sido ela não mobilizada ou recém-escarificada - controlou a enxurrada de modo eficaz e impediu totalmente a erosão. A superfície de solo recém-gradeada sobre a superfície escarificada há um mês, embora com o solo mais mobilizado de todos e descoberto, praticamente não apresentou perdas de solo e água, contrariando o que se esperava.

Termos de indexação: chuva simulada, cobertura do solo, rugosidade do solo, consolidação do solo, infiltração de água no solo, perda de água, perda de solo.

\section{SUMMARY: RESTORATION OF THE SOIL STRUCTURE BY CROP SEQUENCES ESTABLISHED IN NO-TILL, AS RELATED TO WATER EROSION IN DISTINCT SURFACE PHYSICAL CONDITIONS}

Soil structure plays a prominent role in plant growth and erosion control, and consequently in food production and soil and water conservation. This research was developed with the objective of implementing and accompanying the restoration process of the structure of a degraded soil, by planting crop sequences under no-tillage (autumn-winter and spring-summer, grass and legume, in single and intercropped systems), and later verifying the relations with water and soil losses caused by rainfall erosion, under distinct surface physical conditions (untilled soil, with and without crust; freshly-tilled soil by chiseling and by chiseling followed by disking after one month, and crop residue covering 100, 18, and $0 \%$ ). The field study was developed under simulated rainfall, at the Agriculture Experimental Station of the Federal University of Rio Grande do Sul (EEA/UFRGS), in Rio Grande do Sul State, Brazil, from May 2004 to Decembe, 2007. The six erosion tests, in intervals of about a week, were performed from October to December, 2007. The soil used is an Ultisol, with a sandy clay loam texture in the surface layer and $0.115 \mathrm{~m} \mathrm{~m}^{-1}$ average slope steepness, and an advanced degree of degradation. The rains were applied with a rotating-boom rainfall simulator, at a constant intensity of $64 \mathrm{~mm} \mathrm{~h}^{-1}$, for 1-3 $\mathrm{h}$. For this study, water and soil loss data were adjusted to a rainfall duration of $1.5 \mathrm{~h}$. Properties of soil and plants were measured in the experimental plots and water erosion in the surface runoff. The crop sequences and erosion tests influenced the results of the study significantly, with greater differences in the latter than in the former. The erosive process was more influenced by the external or soil surface than the internal or subsurface physical conditions. In general, all crop sequences were effective in restoring the soil structure in the experimental period. The sequence involving teosinte controlled the rainfall erosion process most effectively with regard to soil and water loss and the one involving corn+cowpea and pearl millet with regard to soil loss. The highest soil and water losses in the study were observed from the soil surface with no mobilization and little crop residue cover, regardless of the presence or type of crust, but especially when this latter was slightly cracked prior to rainfall application. The soil surface entirely covered by crop residue, be it untilled or freshly chiseled, controlled runoff effectively and impeded erosion completely. Soil and water losses from the freshly-disked soil surface chiseled a month earlier, although the soil was the most mobilized of all and bare, were practically zero, opposite to what was expected.

Index terms: simulated rainfall, soil cover, soil roughness, soil consolidation, soil water infiltration, water loss, soil loss. 


\section{INTRODUÇÃO}

A degradação do solo, definida por Poch \& Martinez-Casasnova (2002) como o declínio na sua qualidade causado pelo uso impróprio pelo homem, resulta em diminuição ou, mesmo, perda da sua capacidade de desempenhar as funções que lhe são naturalmente devidas ou designadas. $\mathrm{O}$ ponto básico refere-se à diminuição da qualidade da estrutura do solo, podendo ocorrer tanto em superfície, com o aparecimento de finas crostas, quanto em subsuperfície, sob a camada arável, com o surgimento de camadas compactadas, resultando em menores taxas de infiltração de água e maiores de escoamento superficial e de erosão, o que irá acelerar mais ainda o processo de degradação do solo.

A erosão é a mais extensiva e preocupante das oito categorias de degradação antrópica do solo estabelecidas (Hudson, 1995), já que as taxas de desgaste e remoção de solo pela erosão podem superar infinitamente as taxas (naturais e artificiais) de renovação e reposição superficial de solo. Excetuando a erosão, a degradação essencialmente física do solo (sem perda de solo) é a mais fácil e rápida de ser causada e a mais difícil e demorada de ser revertida, especialmente quando as taxas de decomposição dos restos vegetais superam as de reposição, fazendo com que cada vez mais diminua o teor de matéria orgânica e, em decorrência, cada vez menos as plantas respondam às funções do solo. Assim, práticas selecionadas de manejo aumentam o teor de matéria orgânica no solo e melhoram sua estrutura como um todo, incluindo propriedades físicas (densidade do solo, resistência à penetração de raízes, estabilidade de agregados, porosidade e retenção de água), químicas e biológicas, o que irá favorecer o crescimento das plantas, refletindo em maior rendimento das culturas (Mielniczuk \& Schneider, 1984; Schjonning \& Christensen, 1994; Kay, 1998; Mallory \& Porter, 2007; Riley et al., 2008). Assim, práticas que buscam o aporte contínuo e abundante de matéria orgânica ao solo, associadas a métodos conservacionistas de preparo, são de fundamental importância na recuperação de solos fisicamente degradados.

A agregação do solo, processo principal para a sua recuperação, ocorre pela ação combinada da matéria orgânica humificada, atividade biológica e raízes das plantas (Campos et al., 1999; Senesi \& Loffredo, 1999). Para acelerar a recuperação de solos fisicamente degradados, Nuernberg et al. (1986) salientaram a importância do cultivo de plantas com crescimento inicial rápido e intenso, que produzam grande quantidade de raízes profundas e de resíduo cultural; a consorciação de duas ou mais espécies culturais e a rotação adequada de culturas também podem contribuir com a restauração da estrutura do solo. Lal \& Greenland (1979) ressaltaram que as rotações de cultura que incluem pastagens de gramínea com pastagens de leguminosa, além de culturas anuais, são as mais eficientes na criação e manutenção de uma boa estrutura para o solo; as gramíneas influenciam pelo seu sistema radicular extenso e abundante, em constante renovação, e as leguminosas, pelo nitrogênio biologicamente fixado e pela sua baixa relação $\mathrm{C} / \mathrm{N}$. Silva (1993) encontrou alta correlação entre densidade de raízes e grau de agregação e estabilidade de agregados, enquanto Campos et al. (1999) destacaram a importância das raízes finas na profundidade de solo de 0 a $5 \mathrm{~cm}$, as quais, juntamente com a matéria orgânica, envolvem os microagregados do solo, ao mesmo tempo em que atuam na formação e estabilização dos macroagregados. Bruce et al. (1990) observaram influência de um sistema de rotação de culturas nas características físicas do solo somente na semeadura direta, ao passo que os preparos envolvendo mobilização da camada arável eliminaram os efeitos benéficos da rotação de culturas na reestruturação do solo.

A degradação do solo pelo uso e manejo incorretos é fortemente refletida no aumento da erosão e no rebaixamento do teor de matéria orgânica e do nível de fertilidade do solo e, por conseguinte, na diminuição da sua capacidade produtiva para as culturas e na contaminação das fontes superficiais de água (Daily et al., 1997). Estudos sobre a qualidade física do solo para fins de controle da erosão hídrica foram desenvolvidos por Streck $(1999)$ e Volk $(2002,2006)$ no Estado do Rio Grande do Sul. Streck (1999) observou que, após 2,5 anos sem preparar o solo, a sua superfície se consolidou ao ponto em que a erosão foi reduzida em 81 e $93 \%$, respectivamente nos tratamentos sem e com cultivo, comparada à erosão ocorrida no solo recém-preparado pelo método convencional. Volk (2006) também observou que a suspensão do preparo do solo efetivamente consolidou a superfície e resultou em valores decrescentes de perda de solo por erosão hídrica com o passar do tempo, mas com os valores de perda de água permanecendo sempre altos, mesmo estando o solo com grande quantidade de resíduos culturais na superfície; já no solo recém-mobilizado, os valores de perda de água foram bem menores, mesmo estando ele descoberto. Esses dois comportamentos mantiveram-se até o final do período de realização dos testes de erosão com chuva simulada. A menor perda de solo ocorreu no solo não mobilizado com alta quantidade de cobertura por resíduo cultural, secundada pela do solo não mobilizado ou recémmobilizado e ambos sem nenhuma cobertura superficial, aumentando com o passar do tempo e com os preparos de solo subsequentes. A massa de raízes mortas, o diâmetro médio ponderado de agregados e o índice de rugosidade superficial do solo mostraram-se bons indicadores de qualidade física para o propósito de redução da perda total de água em todas as condições físicas estudadas da camada superficial, bem como para o propósito de redução da perda total de solo, excetuando a condição de solo com grande quantidade de cobertura superficial, na qual o efeito das variáveis em consideração foi irrelevante. 
Esta pesquisa foi realizada com os objetivos de avaliar a capacidade de diferentes sequências culturais em semeadura direta na restauração da estrutura de um solo degradado e verificar sua relação com a erosão hídrica em distintas condições físicas de superfície.

\section{MATERIAL E MÉTODOS}

A pesquisa foi realizada em campo, na Estação Experimental Agronômica da Universidade Federal do Rio Grande do Sul (EEA/UFRGS), município de Eldorado do Sul (RS), na região da Depressão Central, no período compreendido entre maio de 2004 e dezembro de 2007. Os testes de erosão - em número de seis e na sua grande maioria espaçados um do outro por cerca de uma semana - foram realizados de outubro a dezembro de 2007. O solo do estudo atualmente encontra-se classificado como Argissolo Vermelho distrófico típico (Embrapa, 2006), possuindo textura franco-argiloarenosa na camada superficial e declividade média de $0,115 \mathrm{~m} \mathrm{~m}^{-1}$. No início da pesquisa esse solo encontrava-se bastante degradado, e a partir dessa condição é que foi dado início ao seu cultivo durante três anos e meio, com vistas à construção dos tratamentos a serem investigados, os quais serão especificados a seguir.

Os cinco tratamentos investigados, com duas repetições contíguas, foram dispostos num delineamento experimental próximo ao completamente casualizado (sorteou-se o par de parcelas destinado a cada tratamento), tendo consistido de sequências culturais variadas implantadas em semeadura direta, nos modos de cultivo isolado e consorciado, particularizadas e distribuídas conforme apresentado no quadro 1.
Para a implantação das culturas de aveia-preta (Avena strigosa), ervilhaca (Vicia sativa), trevoalexandrino (Trifolium alexandrinum) cultivar calypso e azevém (Lolium multiflorum L.), foi utilizada máquina de semeadura direta de fluxo contínuo (propósitos de corte da palha e deposição das sementes na profundidade de solo de $4-6 \mathrm{~cm}$ ); e para a implantação das culturas de milho (Zea mays L.), milheto (Pennisetum americanum), teosinto (Euchlaena mexicana Schrad), feijão-miúdo (Vigna unguiculata) e feijão-de-porco (Canavalia ensiformes L.) foi utilizada máquina de semeadura direta de precisão (propósito de colocação do adubo na profundidade de solo de 10-12 cm).

As condições físicas de superfície do solo criadas na pesquisa (ação programada) para testar as sequências culturais citadas (ação natural) quanto à enxurrada e à erosão, e sobre as quais foram aplicadas as chuvas simuladas, foram as seguintes, em cada teste de erosão: (a) T1 - solo não mobilizado, crosta normal, $100 \%$ de cobertura por resíduos culturais; (b) T2 - solo não mobilizado, crosta levemente rompida, $18 \%$ de cobertura por resíduos culturais, realizado transcorridos oito dias de T1; (c) T3 - solo não mobilizado, crosta tênue formada a partir da finalização de T2, $18 \%$ de cobertura por resíduos culturais, realizado transcorridos cinco dias de T2; (d) T4 - solo recém-escarificado, $100 \%$ de cobertura por resíduos culturais, realizado transcorridos seis dias de T3; (e) T5 - solo previamente escarificado (em T4), $18 \%$ de cobertura por resíduos culturais, realizado transcorridos oito dias de T4; e (f) T6 - solo previamente escarificado (em T4) e recém-gradeado (grade leve), descoberto, realizado transcorridos 20 dias de T5. As operações de preparo do solo e semeadura das culturas foram efetuadas sempre no sentido do declive do terreno, conforme filosofia de obtenção do fator C

Quadro 1. Disposição espacial e temporal das sequências culturais estabelecidas no experimento (tratamentos principais estudados), implantadas em semeadura direta ou sem preparo do solo ${ }^{(1)}$

\begin{tabular}{|c|c|c|c|c|c|c|c|c|}
\hline \multirow{2}{*}{$\begin{array}{l}\text { Par de } \\
\text { parcelas }\end{array}$} & \multicolumn{2}{|c|}{2004} & \multicolumn{2}{|r|}{2005} & \multicolumn{2}{|c|}{2006} & \multirow{2}{*}{$\frac{2007}{\text { Out.-Inv. }}$} & \multirow{2}{*}{$\begin{array}{c}\text { Convenção } \\
\text { usada }\end{array}$} \\
\hline & Out.-Inv. ${ }^{(2)}$ & Prim. Ver ${ }^{(3)}$ & Out.-Inv. & Prim.-Ver. & Out.-Inv. & Prim.-Ver. & & \\
\hline 1 e 2 & Aveia-preta & Feijão-miúdo & $\begin{array}{l}\text { Aveia-preta } \\
+ \text { Ervilhaca }\end{array}$ & Feijão-miúdo & $\begin{array}{l}\text { Aveia-preta } \\
+ \text { Ervilhaca }\end{array}$ & Feijão-miúdo & $\begin{array}{l}\text { Aveia-preta } \\
+ \text { Ervilhaca }\end{array}$ & $1 \mathrm{Av}, 3 \mathrm{Av}+\mathrm{Er} / 3 \mathrm{Fm}$ \\
\hline 3 e 4 & Aveia-preta & Feijão-miúdo & Aveia-preta & Teosinto & Aveia-preta & Teosinto & Aveia-preta & $4 \mathrm{Av} / 1 \mathrm{Fm}, 2 \mathrm{Te}$ \\
\hline 5 e 6 & Aveia-preta & Feijão-miúdo & $\begin{array}{l}\text { Trevo } \\
\text { alexandrino }\end{array}$ & $\begin{array}{l}\text { Milho + } \\
\text { Feijão-miúdo }\end{array}$ & $\begin{array}{l}\text { Nabo } \\
\text { forrageiro }\end{array}$ & $\begin{array}{l}\text { Milho + } \\
\text { Feijão-miúdo }\end{array}$ & Azevém & $\begin{array}{l}1 \mathrm{Av}, \mathrm{Tr}, \mathrm{Nf}, \mathrm{Az} / 1 \mathrm{Fm}, \\
2 \mathrm{Mi}+\mathrm{Fm}\end{array}$ \\
\hline 7 e $8^{(4)}$ & Sem cultivo & Feijão-miúdo & $\begin{array}{l}\text { Aveia-preta } \\
+ \text { Ervilhaca }\end{array}$ & Milheto & $\begin{array}{l}\text { Aveia-preta }+ \\
\text { Nabo forrageiro }\end{array}$ & Milheto & $\begin{array}{l}\text { Aveia-preta } \\
+ \text { Azevém }\end{array}$ & $\begin{array}{l}\text { 1Sc,Av+Er,Av+Nf, } \\
\mathrm{Av}+\mathrm{Az} / 1 \mathrm{Fm}, 2 \mathrm{Mt}\end{array}$ \\
\hline 9 e 10 & Aveia-preta & Feijão-miúdo & Ervilhaca & $\begin{array}{l}\text { Milho }+ \\
\text { Feijão-de-porco }\end{array}$ & Ervilhaca & $\begin{array}{l}\text { Milho }+ \\
\text { Feijão-de-porco }\end{array}$ & Ervilhaca & $\begin{array}{l}1 \mathrm{Av}, 3 \mathrm{Er} / 1 \mathrm{Fm}, \\
2 \mathrm{Mi}+\mathrm{Fp}\end{array}$ \\
\hline
\end{tabular}

(1) Excetuando o cultivo de aveia-preta no período de out.-inv. de 2004, o qual foi executado após o solo ter sido mobilizado com grade leve ou niveladora, para incorporação do calcário e do adubo por ocasião da adequação da área experimental. ${ }^{(2)}$ Out.-Inv.: outono-inverno. ${ }^{(3)}$ Prim-Ver.: primavera-verão. ${ }^{(4)}$ Parcelas unitárias ("padrão") de Wischmeier \& Smith (1978), continuamente preparadas pelo método convencional (1 aração+2 gradagens) e mantidas sem cultivo e livres de vegetação espontânea ou permanentemente descobertas. 
(cobertura e manejo do solo) dos modelos USLE e RUSLE de predição da erosão hídrica (Wischmeier \& Smith, 1978; Renard et al., 1997).

As chuvas simuladas foram aplicadas com o aparelho simulador de braços rotativos (Swanson, 1965), na intensidade constante planejada de $64,0 \mathrm{~m} \mathrm{~m} \mathrm{~h}^{-1}$ (intensidade-padrão comum e universalmente usada em estudos dessa natureza) e com duração variando de 1 a $3 \mathrm{~h}$, almejando-se atingir a condição de equilíbrio da enxurrada em todos os testes de erosão; como isso não foi alcançado na grande maioria dos casos, as perdas totais de água e solo neste trabalho foram ajustadas para a duração única de chuva de $1,5 \mathrm{~h}$, para coerentemente poder analisar e interpretar os resultados obtidos. O tempo de início da enxurrada e a altura da lâmina de água da chuva retida e, ou, infiltrada na superfície do solo no período pré-enxurrada, pelo fato de às vezes terem superado a duração da chuva usada no ajuste, foram registrados e analisados conforme os valores observados.

Mediu-se a cobertura do solo por resíduos culturais usando o método da linha de transeção de pontos (Hartwig \& Laflen, 1978); a biomassa aérea ou dossel das plantas, por meio da coleta destas últimas em uma área de $1 \mathrm{~m}^{2}$, em dois locais dentro da parcela experimental, secagem em estufa a $60{ }^{\circ} \mathrm{C}$ e pesagem; a biomassa subterrânea ou raízes das culturas, por meio da coleta de um volume de solo $\left(173,5 \mathrm{~cm}^{3}\right)$ contendo raízes, usando trado cilíndrico, em seis locais dentro de cada parcela experimental, nas profundidades de $0-10$ e $10-20 \mathrm{~cm}$, seguida da separação das raízes do solo por lavagem da amostra sob jato de água de torneira, secagem em estufa a $60{ }^{\circ} \mathrm{C}$ e pesagem; a densidade do solo, pelo método do anel volumétrico (Forsythe, 1975); a porosidade total do solo, pelo método do anel volumétrico (Danielson \& Sutherland, 1986); a macroporosidade do solo, pelo método da mesa de tensão (Bouma, 1973); o diâmetro médio ponderado (DMP) de agregados do solo, pela técnica de peneiramento úmido (Kemper \& Chepil, 1965); o teor de água no solo antecedente às chuvas simuladas, pelo método gravimétrico (Forsythe, 1975); o tempo de início da enxurrada (Ti), com cronômetro, a partir do início das chuvas; a lâmina de água da chuva superficialmente retida e, ou, infiltrada no solo no período pré-enxurrada (LAPE), por cálculo direto, usando os valores observados de intensidade das chuvas e tempos de início da enxurrada; a perda total de água (PTA), por integração das taxas instantâneas de descarga da enxurrada, medidas a cada três minutos, diretamente sob seu fluxo; e a perda total de solo (PTS), por integração das taxas instantâneas de perda de solo, obtidas a cada três minutos, por meio da multiplicação dos valores de concentração instantânea de sedimentos na enxurrada com os de taxa instantânea de descarga desta (Cogo, 1981) e usando o programa computacional PEDEROSÃO, desenvolvido pelo professor Elemar Antonino Cassol, do Departamento de Solos da Faculdade de Agronomia da UFRGS. Os resultados foram submetidos à análise da variância, com as médias tendo sido comparadas pelo teste de Tukey a $10 \%$, usando o programa SPSS/ V18.0, disponível em "site" da UFRGS aos seus professores. A interpretação dos resultados, em adição à consideração estatística, foi baseada em teorias $\mathrm{e}$ conceitos desenvolvidos em estudos de mecânica da erosão hídrica pluvial do solo, encontrados na literatura especializada.

\section{RESULTADOS E DISCUSSÃO}

\section{Variáveis de manejo do solo}

No quadro 2 são apresentados os resultados do teor de matéria orgânica e de alguns atributos físicos do solo em duas profundidades, na condição original de campo nativo e na condição alterada por ação antrópica intensa - esta última correspondendo ao início da presente pesquisa. Analisando os dados, com base no teor de matéria orgânica (MO) e, especialmente, no diâmetro médio ponderado (DMP) de agregados, verificou-se que o solo se encontrava degradado no início da pesquisa, com os valores das variáveis em consideração (média das profundidades de 0-10 e 10$20 \mathrm{~cm}$ ) correspondendo a, respectivamente, 70 e $25 \%$ dos valores originais (campo nativo). Isso deveu-se a um estudo anterior conduzido na mesma área experimental (Volk, 2006), em que o solo foi suspenso

Quadro 2. Composição granulométrica, teor de matéria orgânica (MO), diâmetro médio ponderado (DMP) de agregados, densidade (Ds) e porosidade total $(\mathrm{Pt})$ do solo, avaliados em fevereiro de 1995, na condição original de campo nativo (Badelucci, 1997), e em abril de 2004, na condição alterada por ação antrópica intensa (Volk, 2006), esta última correspondendo ao início da presente pesquisa

\begin{tabular}{|c|c|c|c|c|c|c|c|c|c|}
\hline \multirow{2}{*}{ Camada do solo } & \multicolumn{3}{|c|}{ Composição granulométrica } & \multicolumn{4}{|c|}{ Condição física original } & \multicolumn{2}{|c|}{ Condição física alterada } \\
\hline & Areia & Silte & Argila & MO & DMP & Ds & $\mathbf{P t}$ & MO & DMP \\
\hline $\mathrm{cm}$ & & $\mathrm{g} \mathrm{kg}^{-1}$ & & $\mathrm{~g} \mathrm{~kg}^{-1}$ & $\mathrm{~mm}$ & $\mathrm{~kg} \mathrm{dm}^{-3}$ & $\mathrm{~m}^{3} \mathrm{~m}^{-3}$ & $\mathrm{~g} \mathrm{~kg}-1^{-1}$ & $\mathrm{~mm}$ \\
\hline $0-10$ & 560 & 180 & 260 & 30 & 4,1 & 1,50 & 0,45 & 19,0 & 1,0 \\
\hline $10-20$ & 550 & 310 & 310 & 21 & 3,5 & 1,66 & 0,38 & 18,0 & 0,9 \\
\hline
\end{tabular}


do processo de cultivo e sofreu a ação consecutiva de sete chuvas simuladas, cinco delas com a sua superfície sendo sucessivamente gradeada em relativamente curto espaço de tempo (seis meses) e mantida sempre descoberta. Como mencionado por Mielniczuk \& Schneider (1984), Six et al. (2002), Spera et al. (2004) e Stone \& Guimarães (2005), a atividade agrícola mal conduzida, com preparos intensos e cultivos inadequados, efetivamente altera a quantidade e a qualidade da matéria orgânica do solo e acelera o processo de deterioração da sua estrutura, o que negativamente irá afetar a produção vegetal e predispôlo ainda mais à ação dos agentes erosivos.

No quadro 3 são apresentados os resultados de biomassa vegetal aérea ou dossel e biomassa vegetal subterrânea ou raízes das culturas que estavam na área experimental por ocasião da avaliação, referentes a dois ciclos culturais de primavera-verão e um ciclo cultural de outono-inverno, obtidos no último ano e meio de experimentação (março de 2006 a outubro de 2007). Analisando os dados, verificou-se que, na maior parte dos casos, as sequências culturais diferenciaram-se significativamente quanto às produções de biomassa (aérea e subterrânea), porém sem regularidade quanto à ordem de ocorrência das significâncias no que se refere tanto às épocas de avaliação ou ciclos culturais quanto às profundidades do solo avaliadas - neste caso, para a biomassa vegetal subterrânea ou raízes. Essa irregularidade nos resultados parcialmente deveu-se a fontes de variação involuntária e circunstancialmente introduzidas na pesquisa, como estiagens ocasionais e operações de ressemeadura e entrada de animais silvestres nas parcelas experimentais acontecidas de modo desigual, conforme mais detalhadamente relatado em Portela (2009). Variação nos resultados em ordem semelhante à ocorrida neste trabalho foi também observada por Carvalho \& Amabile (2006), em estudo com diferentes espécies vegetais, em função do ambiente (temperatura e precipitação pluvial), das características intrínsecas de cada espécie vegetal (fotoperíodo) e de atributos químicos, físico-hídricos e biológicos do solo, resultando em oscilações significativas quanto à produção de fitomassa.

Independentemente do que foi narrado, observouse no quadro 3 a larga predominância das culturas de primavera-verão sobre as de outono-inverno no que se refere às produções de biomassas aérea e subterrânea, bem como a larga predominância desta última na profundidade de 0-10 cm, em comparação com 10$20 \mathrm{~cm}$, para qualquer dos grupos ou tipos de cultura (primavera-verão ou outono-inverno). A média dos valores de biomassa aérea e biomassa subterrânea para os dois ciclos culturais de primavera-verão avaliados no experimento mostrou valores, respectivamente, 3,15 vezes $(215 \%)$ e 2 vezes (100 \%) maiores que a média para o ciclo cultural de outonoinverno, bem como 1,3 vez (30 \%) mais biomassa aérea em relação à biomassa subterrânea no total das duas profundidades avaliadas $(0-20 \mathrm{~cm})$ para as culturas de primavera-verão e $0,80 \mathrm{vez}(20 \%)$ menos para as culturas de outono-inverno. A quantidade de raízes na profundidade de $0-10 \mathrm{~cm}$ foi ao redor de 3,8 (280 \%) vezes maior do que a observada de $10-20 \mathrm{~cm}$, representando cerca de $80 \%$ delas concentradas na primeira profundidade referida, em relação ao total

Quadro 3. Biomassas aérea (dossel) e subterrânea (raízes) em três épocas e duas profundidades, avaliadas no último ano e meio de experimentação, nos tratamentos de sequência cultural estudados

\begin{tabular}{|c|c|c|c|c|c|c|c|c|c|c|c|c|}
\hline \multirow{3}{*}{$\begin{array}{l}\text { Sequência } \\
\text { cultural }^{(1)}\end{array}$} & \multicolumn{4}{|c|}{$\begin{array}{l}\text { 21/03/06 - } 4 \text { meses após a semeadura, } \\
\text { culturas de verão, plantas em } \\
\text { crescimento, solo não mobilizado }\end{array}$} & \multicolumn{4}{|c|}{$\begin{array}{c}\text { 13/02/07 - 3,5 meses após a semeadura, } \\
\text { culturas de verão, plantas em } \\
\text { crescimento, solo não mobilizado }\end{array}$} & \multicolumn{4}{|c|}{$\begin{array}{c}\text { 09/10/2007 - } 4 \text { meses após a semeadura } \\
\text { culturas de inverno, plantas em } \\
\text { crescimento, solo não mobilizado }\end{array}$} \\
\hline & \multirow{2}{*}{$\begin{array}{l}\text { Biomassa } \\
\text { aérea }\end{array}$} & \multicolumn{3}{|c|}{ Biomassa subterrânea } & \multirow{2}{*}{$\begin{array}{c}\text { Biomassa } \\
\text { aérea }\end{array}$} & \multicolumn{3}{|c|}{ Biomassa subterrânea } & \multirow{2}{*}{$\begin{array}{c}\text { Biomassa } \\
\text { aérea }\end{array}$} & \multicolumn{3}{|c|}{ Biomassa subterrânea } \\
\hline & & $0-10 \mathrm{~cm} 1$ & $10-20 \mathrm{~cm}$ & $0-20 \mathrm{~cm}$ & & $0-10 \mathrm{~cm}$ & $10-20 \mathrm{~cm}$ & $0-20 \mathrm{~cm}$ & & $0-10 \mathrm{~cm}$ & $10-20 \mathrm{~cm}$ & $0-20 \mathrm{~cm}$ \\
\hline $1 \mathrm{Av}, 3 \mathrm{Av}+\mathrm{Er} / 3 \mathrm{Fm}$ & $7989 \mathrm{~b}$ & $5755 \mathrm{~s}$ & 993 & 6748 & 4545 & 4554 & 2322 & 6875 & $742 \mathrm{gh}$ & $2755 \mathrm{R}$ & 016 & 36729 \\
\hline $4 \mathrm{Av} / 1 \mathrm{Fm}, 2 \mathrm{Te}$ & $25.569 \mathrm{a}$ & $14.820 \mathrm{a}$ & $954 \mathrm{a}$ & $15.774 \mathrm{c}$ & $21.094 \mathrm{~d}$ & $15.179 \mathrm{a}$ & $7.634 \mathrm{~b}$ & $22.814 \mathrm{~b}$ & $5.721 \mathrm{bc}$ & $5.003 \mathrm{a}$ & $807 \mathrm{a}$ & $5.810 \mathrm{a}$ \\
\hline $\begin{array}{l}\text { 1Av, Tr, Nf,Az/1Fm, } \\
2 \mathrm{Mi}+\mathrm{Fm}\end{array}$ & $17.719 \mathrm{ab}$ & $11.816 \mathrm{ab}$ & $2.583 \mathrm{~b}$ & $14.399 \mathrm{bc}$ & $11.429 \mathrm{~b}$ & $4.464 \mathrm{a}$ & $2.009 \mathrm{a}$ & $6.474 \mathrm{a}$ & $3.961 \mathrm{a}$ & $5.188 \mathrm{a}$ & $1.470 \mathrm{a}$ & $6.657 \mathrm{a}$ \\
\hline $\begin{array}{l}\mathrm{Sc}, \mathrm{Av}+\mathrm{Er}, \mathrm{Av}+\mathrm{Nf} \\
\mathrm{Av}+\mathrm{Az} / 1 \mathrm{Fm}, 2 \mathrm{Mt}\end{array}$ & $26.309 \mathrm{a}$ & $10.259 \mathrm{abc}$ & c $1.329 \mathrm{a}$ & $11.589 \mathrm{abc}$ & $15.346 \mathrm{c}$ & $8.884 \mathrm{a}$ & $2.188 \mathrm{a}$ & $11.072 \mathrm{ab}$ & $6.166 \mathrm{c}$ & $6.035 \mathrm{a}$ & $1.026 \mathrm{a}$ & $7.061 \mathrm{a}$ \\
\hline $1 \mathrm{Av}, 3 \mathrm{Er} / 1 \mathrm{Fm}, 2 \mathrm{Mi}+\mathrm{Fp}$ & $15.599 \mathrm{ab}$ & $7.862 \mathrm{bc}$ & $1.314 \mathrm{a}$ & $9.176 \mathrm{ab}$ & $9.459 \mathrm{~b}$ & $9.402 \mathrm{a}$ & $4.286 \mathrm{ab}$ & $13.688 \mathrm{ab}$ & $4.053 \mathrm{a}$ & $4.836 \mathrm{a}$ & $1.620 \mathrm{a}$ & $6.456 \mathrm{a}$ \\
\hline $\mathrm{CV}(\%)$ & 41,1 & 34,7 & 47,0 & 32,4 & 47,9 & $58,2 \mathrm{a}$ & 69,1 & 58,8 & 19,9 & 48,1 & 49,2 & 40,3 \\
\hline
\end{tabular}

(1) Nas sequências culturais listadas, implantadas em semeadura direta, o algarismo precedendo a cultura ou combinação de culturas indica o número de vezes que ela tomou parte no experimento, enquanto a cultura ou combinação de culturas sublinhada significa que era ela a que vigia no momento da avaliação, no ciclo cultural em questão, sendo as seguintes para as convenções adotadas: Av: aveia-preta, Er: ervilhaca, Fm: feijão-miúdo, Te: teosinto, Tr: trevo-calypso, Nf: nabo forrageiro, Az: azevém, Mi: milho, Sc: sem cultivo, Mt: milheto e Fp: feijão-de-porco. Valores nas colunas seguidos da mesma letra não diferem estatisticamente entre si pelo teste de Tukey a $10 \%$ 
de $0-20 \mathrm{~cm}$. Ainda com os mesmos tipo de cálculo e forma de comparação, de modo geral, verificou-se no quadro 3 que as sequências culturais que mais produziram biomassa vegetal (aérea e subterrânea) foram as que, por ocasião da avaliação, tinham nas parcelas experimentais o teosinto, o milheto e o milho + feijão-miúdo, porém destacando-se a com o teosinto. Em princípio, julgou-se que os resultados apresentados e discutidos, apesar da variação neles ocorrida, estão dentro da faixa de normalidade no que se refere tanto aos tipos ou grupos de cultura quanto às profundidades avaliadas.

No quadro 4 são apresentados os resultados do teor de matéria orgânica e de alguns atributos físicos do solo, obtidos ao término do período experimental (3,5 anos do início da pesquisa), verificando-se diferenças estatisticamente significativas entre os tratamentos apenas para o teor de matéria orgânica (MO) nas profundidades de 0-10 e 10-20 cm e para o diâmetro médio ponderado de agregados (DMP) de 0 $10 \mathrm{~cm}$. Comparando esses resultados com os do quadro 2 (solo na condição original de campo nativo e na alterada por ação antrópica intensa ou início da pesquisa), verificou-se que, de modo geral, todas as sequências culturais foram eficazes na restauração da estrutura do solo durante o período de cultivo com elas, sobressaindo a com teosinto. Na média das sequências culturais, o teor de MO de $0-10 \mathrm{~cm}$ foi acrescido em $35 \%$ e o valor de DMP em $202 \%$, em relação aos valores do início da pesquisa, quando o solo se encontrava degradado, tendo chegado, respectivamente, aos 85 e $75 \%$ dos valores originais (campo nativo). Essa expressiva melhoria deveu-se ao contínuo aporte de material vegetal ao solo, principalmente por meio das raízes das plantas, conforme também mencionado por Silva \& Mielniczuk (1997) e Campos et al. (1999). Verificou-se ainda que, de modo geral, houve tendência de aumento da densidade do solo e, em decorrência, diminuição da macroporosidade (Ma) e da porosidade total (Pt) com o tempo de cultivo, independentemente das sequências culturais, em relação aos valores originais sob campo nativo (Quadro 2). Isso pode ser explicado pela ausência de mobilização do solo e, portanto, consolidação da sua superfície no período experimental, conforme também verificado por Stone \& Silveira (2001) e Bertol et al. (2004) em estudos como este, os quais observaram maior densidade do solo de 0-10 cm na semeadura direta do que no preparo convencional e no campo nativo, com correspondente diminuição do volume de macroporos. Segundo Kiehl (1979), a porosidade total do solo considerada ideal para o crescimento de plantas deve ser ao redor de $0,50 \mathrm{~m}^{3} \mathrm{~m}^{-3}$, com um terço dela constituído de macroporos e dois terços, de microporos. Em relação a essa referência, verificou-se que os valores de porosidade total observados ao final do período de experimentação (Quadro 4) são baixos, o que poderá se refletir em baixas taxas de infiltração de água no solo e, por conseguinte, em altas taxas e quantidades totais de perda de água e solo por erosão hídrica. Por subtração dos macroporos da porosidade total, verificou-se também (Quadro 4) predominância de microporos no final do período experimental, principalmente de 10-20 cm, inclusive ultrapassando os dois terços citados por Kiehl (1979).

\section{Variáveis de erosão hídrica do solo}

Antes de discutir os dados dessas variáveis, é fundamental mencionar que o teor de água no solo antecedente às chuvas simuladas, exceto o da profundidade de 10-20 cm nos dois primeiros testes de erosão (T1 e T2), não diferiu entre as sequências culturais, nem do ponto de vista estatístico nem do ponto de vista de aplicação prática dos resultados, na

Quadro 4. Teor de matéria orgânica (MO), diâmetro médio ponderado (DMP) de agregados, densidade do solo (Ds), macroporosidade (Ma) e porosidade total (Pt) em duas profundidades do solo, obtidos ao final do período experimental (3,5 anos do início da pesquisa), nos tratamentos de sequência cultural estudados

\begin{tabular}{|c|c|c|c|c|c|c|c|c|c|c|}
\hline \multirow{2}{*}{ Sequência cultural(1) } & \multicolumn{2}{|c|}{ MO } & \multicolumn{2}{|c|}{ DMP } & \multicolumn{2}{|c|}{ Ds } & \multicolumn{2}{|c|}{ Ma } & \multicolumn{2}{|c|}{$\mathbf{P t}$} \\
\hline & $0-10 \mathrm{~cm}$ & $10-20 \mathrm{~cm}$ & $0-10 \mathrm{~cm}$ & $10-20 \mathrm{~cm}$ & $0-10 \mathrm{~cm}$ & $10-20 \mathrm{~cm}$ & $0-10 \mathrm{~cm}$ & $10-20 \mathrm{~cm}$ & $0-10 \mathrm{~cm}$ & $10-20 \mathrm{~cm}$ \\
\hline & \multicolumn{2}{|c|}{$\mathrm{g} \mathrm{kg}^{-1}$} & \multicolumn{2}{|c|}{$-\mathrm{mm}$} & \multicolumn{2}{|c|}{$\mathrm{kg} \mathrm{dm}^{-3}$} & \multicolumn{2}{|c|}{$-\mathrm{mm}=$} & \multicolumn{2}{|c|}{$-\mathrm{m}^{3} \mathrm{~m}^{-3}$} \\
\hline $1 \mathrm{Av}, 3 \mathrm{Av}+\mathrm{Er} / 3 \mathrm{Fm}$ & $22 \mathrm{a}$ & $16 \mathrm{ab}$ & $2,85 \mathrm{ab}$ & $1,09 \mathrm{a}$ & $1,70 \mathrm{a}$ & $1,68 \mathrm{a}$ & $0,112 \mathrm{a}$ & $0,096 \mathrm{a}$ & $0,368 \mathrm{a}$ & $0,362 \mathrm{a}$ \\
\hline $4 \mathrm{Av} / 1 \mathrm{Fm}, 2 \mathrm{Te}$ & $31 \mathrm{~b}$ & $19 \mathrm{~b}$ & $3,50 \mathrm{~b}$ & $1,72 \mathrm{a}$ & $1,63 \mathrm{a}$ & $1,70 \mathrm{a}$ & $0,146 \mathrm{a}$ & $0,095 \mathrm{a}$ & $0,397 \mathrm{a}$ & $0,351 \mathrm{a}$ \\
\hline 1Av,Tr,Nf,Az/1Fm,2Mi+Fm & $23 \mathrm{a}$ & $16 \mathrm{ab}$ & $3,00 \mathrm{ab}$ & $1,56 \mathrm{a}$ & $1,67 \mathrm{a}$ & $1,66 \mathrm{a}$ & $0,115 \mathrm{a}$ & $0,080 \mathrm{a}$ & $0,362 \mathrm{a}$ & $0,357 \mathrm{a}$ \\
\hline $1 \mathrm{Sc}, \mathrm{Av}+\mathrm{Er}, \mathrm{Av}+\mathrm{Nf}, \mathrm{Av}+\mathrm{Az} / 1 \mathrm{Fm}, 2 \mathrm{Mt}$ & $26 a b$ & $16 \mathrm{ab}$ & $3,23 \mathrm{ab}$ & $1,33 \mathrm{a}$ & $1,75 \mathrm{a}$ & $1,67 \mathrm{a}$ & $0,093 \mathrm{a}$ & $0,077 \mathrm{a}$ & $0,347 \mathrm{a}$ & $0,329 \mathrm{a}$ \\
\hline $1 \mathrm{Av}, 3 \mathrm{Er} / 1 \mathrm{Fm}, 2 \mathrm{Mi}+\mathrm{Fp}$ & $26 a b$ & $19 \mathrm{~b}$ & $2,53 \mathrm{a}$ & $1,29 \mathrm{a}$ & $1,62 \mathrm{a}$ & $1,62 \mathrm{a}$ & $0,091 \mathrm{a}$ & $0,090 \mathrm{a}$ & $0,353 \mathrm{a}$ & $0,353 \mathrm{a}$ \\
\hline CV (\%) & 14,3 & 9,0 & 13,3 & 28,6 & 3,6 & 2,1 & 23,7 & 24,9 & 7,2 & 5,7 \\
\hline
\end{tabular}

(1) Nas sequências culturais listadas, implantadas em semeadura direta, o algarismo precedendo a cultura ou combinação de culturas indica o número de vezes que ela tomou parte no experimento, enquanto a cultura ou combinação de culturas sublinhada significa que era ela a que vigia no momento da avaliação, no ciclo cultural em questão, sendo as seguintes para as convenções adotadas: Av: aveia-preta, Er: ervilhaca, Fm: feijão-miúdo, Te: teosinto, Tr: trevo-calypso, Nf: nabo forrageiro, Az: azevém, Mi: milho, Sc: sem cultivo, Mt: milheto e Fp: feijão-de-porco. Valores nas colunas seguidos da mesma letra não diferem estatisticamente entre si pelo teste de Tukey a $10 \%$. 
maior parte das vezes tendo ficado na faixa de 0,10 a $0,13 \mathrm{~kg} \mathrm{~kg}^{-1}$ de $0-10 \mathrm{~cm}$ e de 0,12 a $15 \mathrm{~kg} \mathrm{~kg}^{-1}$ de 10 $20 \mathrm{~cm}$ (Portela, 2009). Assim, pode-se assumir que a umidade antecedente do solo não constituiu causa de variação no tocante aos resultados das variáveis de erosão hídrica consideradas na pesquisa.

Analisando os resultados da figura $1 \mathrm{a}, \mathrm{b}$, verificaramse diferenças estatisticamente significativas entre as sequências culturais em todos os testes de erosão, tanto para o tempo de início de enxurrada (Ti - Figura 1a) neste caso, exceto no quarto teste (T4) - quanto para a altura da lâmina de água da chuva superficialmente retida e, ou, infiltrada no solo no período pré-enxurrada (LAPE - Figura 1b), porém sem regularidade quanto à ordem de ocorrência das significâncias. De qualquer forma, a sequência cultural envolvendo teosinto, em todos os testes de erosão, destacou-se, apresentando os maiores valores das variáveis em consideração, o que pode ser explicado pelos seus maiores teor de matéria orgânica e diâmetro médio ponderado de agregados do solo no final do período experimental (Quadro 4), possivelmente tendo favorecido a infiltração da água da chuva. Independentemente das sequências culturais avaliadas, os menores valores de Ti e LAPE estiveram associados aos três primeiros testes de erosão (T1, T2 e T3), principalmente ao segundo (T2) e ao terceiro (T3); a superfície do solo nesses três testes ainda não havia sido mobilizada, embora em T1 estivesse com integral cobertura por resíduo cultural (100 \%) e portando crosta (normal), e em T2 e T3 apresentasse pouca cobertura (18\%), com T2 tendo sua crosta (normal, como em T1) levemente rompida antes da aplicação da chuva e T3 com a presença de crosta tênue de formação recente (cinco dias, contados a partir da última chuva ou de T2). Por sua vez, os maiores valores de Ti e LAPE ocorreram nos três ultimos testes de erosão (T4, T5 e T6), sobretudo em T6; a superfície do solo nesses três testes encontrava-se mobilizada, com a de T4 recémescarificada e com integral cobertura por resíduo cultural (100 \%), a de T5 escarificada há uma semana (em T4) e com pouca cobertura por resíduo cultural $(18 \%)$ e a de T6 recém-gradeada por sobre a escarificação realizada há um mês (em T4), sem nenhuma cobertura e tendo já recebido duas aplicações de chuva em T4 e T5: a primeira com $100 \%$ e a segunda com $18 \%$ de cobertura por resíduo cultural. É oportuno ressaltar que, quanto maior o retardamento da enxurrada, tanto maior a quantidade de água da chuva a ser retida e, ou, infiltrada na superfície do solo para posterior aproveitamento pelas plantas. A esse respeito, de modo geral, somente as sequências culturais associadas a T2 e T3 não mostraram resultados satisfatórios, com a altura da lâmina de água da chuva na faixa de 7 a $12 \mathrm{~mm}$, na maior parte dos casos (Figura 1b), devido à não mobilização do solo e, em decorrência, à praticamente nula rugosidade superficial do solo (também praticamente nula porosidade adicional causada pelo preparo - microdepressões ou vazios superficiais) em
T1, T2 e T3, com pouca influência da cobertura por resíduo cultural em cada um deles; o contrário ocorreu em T4, T5 e T6, devido à recente mobilização do solo e, em decorrência, à sua grande rugosidade superficial (também grande porosidade adicionada pelo preparo), com menos influência ainda das suas coberturas por resíduo cultural. Cogo (1981), Cogo et al. (1983) e Castro et al. (2006) ressaltaram que, apesar de efêmera, a rugosidade superficial do solo induzida pelos métodos de preparo constitui requerimento importante nos sistemas de manejo de caráter conservacionista, independentemente da cobertura por resíduos culturais, tendo em vista que ela efetivamente aumenta a retenção e a infiltração superficiais da água da chuva no solo, reduz a velocidade e o volume do escoamento superficial e aprisiona as partículas erodidas, diminuindo as perdas de água e solo por erosão hídrica.

Analisando os resultados da figura 1c,d, referentes às variáveis de erosão hídrica propriamente ditas, diferenças estatisticamente significativas foram verificadas entre as sequências culturais nos três primeiros testes de erosão (T1, T2 e T3) quanto à perda total de água (Figura 1c), e em T2, T3 e T5, quanto à perda total de solo (Figura 1d); ambas as perdas foram praticamente nulas em T6, e a perda total de solo foi essencialmente nula em $\mathrm{T} 1 \mathrm{e}$ T4, independentemente das sequências culturais. Mais uma vez, esses comportamentos não tiveram regularidade quanto à ordem de ocorrência das significâncias e, novamente, a sequência cultural envolvendo teosinto, de modo geral, destacou-se, apresentando os menores valores para as perdas totais de água e de solo (nos casos em que houve erosão). Esse último fato pode ser explicado pelo maior teor de matéria orgânica e maior diâmetro médio ponderado de agregados na sequência cultural que envolveu teosinto (Quadro 4), resultando em maiores tempos de início da enxurrada (Figura 1a) e alturas da lâmina de água da chuva superficialmente retida e, ou, infiltrada no solo no período pré-enxurrada (Figura 1b), o que aumentou a capacidade de infiltração de água do solo e sua resistência física à erosão, conforme já discutido.

No que se refere aos testes de erosão em si, as maiores perdas totais de água e solo estiveram associadas a T2 e T3, cujas superfícies do solo encontravam-se não mobilizadas e continham pouca cobertura por resíduo cultural (18 \%), em que pese a de T2 ter tido sua crosta (normal, a mesma existente em T1) levemente rompida antes da aplicação da chuva e a de T3 estar portando crosta tênue de formação recente (cinco dias, contados da última chuva ou de T2). Isso pode ser explicado pela pouca proteção à superfície do solo contra a ação erosiva e pela pequena rugosidade superficial para reter e infiltrar água da chuva (também reter partículas erodidas) nesses testes, como também argumentado por Cogo (1981), Cogo et al. (1983) e Norton et al. (1985). Devido à integral cobertura por resíduo cultural (100\%), o primeiro teste de erosão (T1), embora também com a 

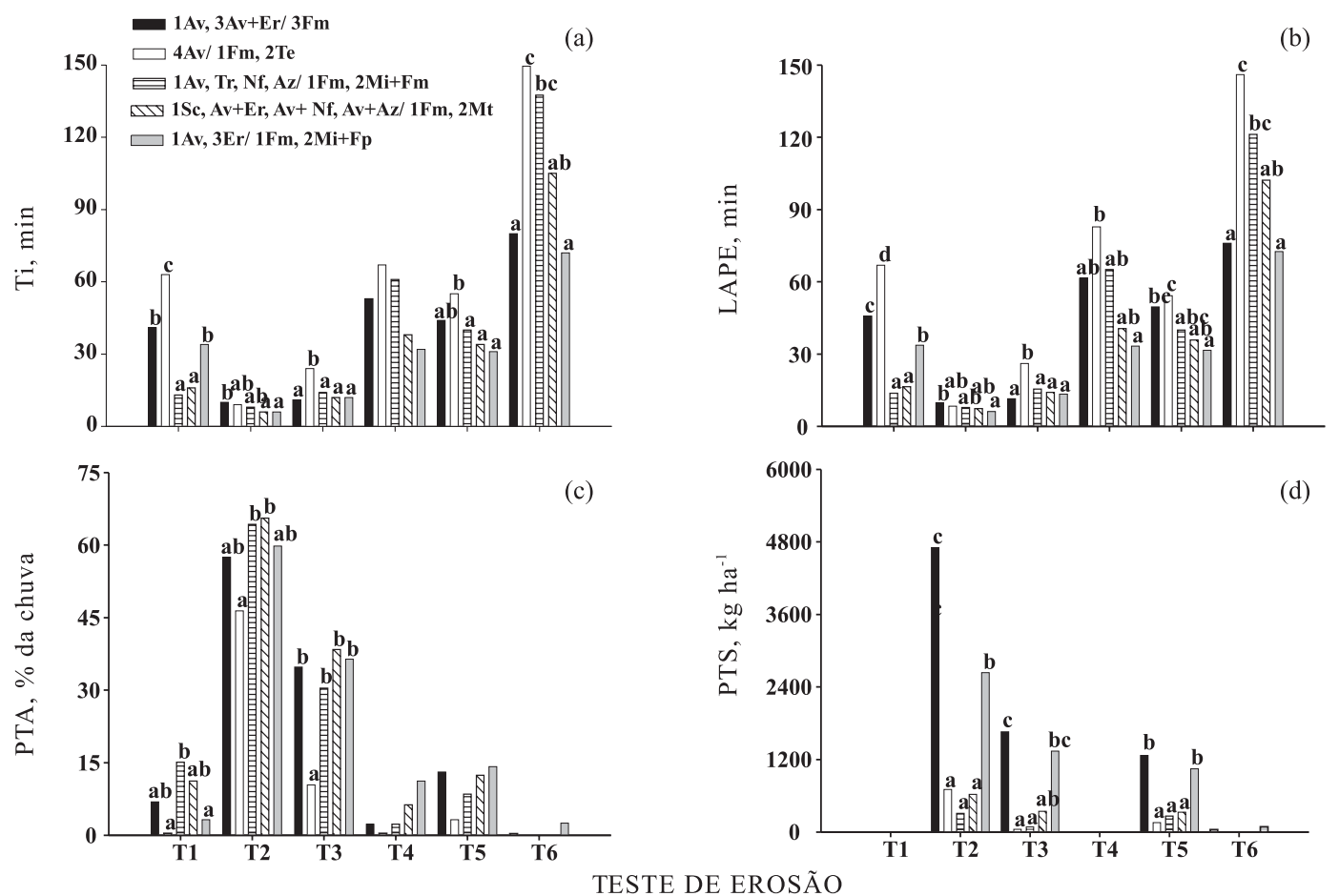

Figura 1. Tempo de início da enxurrada ( $\mathrm{Ti}$ - a), lâmina de água retida no sistema no período pré-enxurrada $(\mathrm{LAPE}-\mathrm{b})$, perda total de água (PTA - d) e perda total de solo (PTS - d) nas sequências culturais estudadas, nos testes de erosão realizados na pesquisa (T1: solo não mobilizado, crosta normal, $100 \%$ coberto; T2: solo não mobilizado, crosta rompida, 18\% coberto; T3: solo não mobilizado, crosta tênue, $18 \%$ coberto; T4: solo recém-escarificado, $100 \%$ coberto; T5: solo previamente escarificado - em T4 $18 \%$ coberto, T6: solo recém-gradeado - após T5 - descoberto). Colunas sobrepostas pela mesma letra, no mesmo teste de erosão, não diferem estatisticamente entre si pelo teste de Tukey a $10 \%$, enquanto ausência de letra nelas representa falta de significância estatística.

superfície do solo não mobilizada e, em decorrência, com mínima rugosidade superficial, apresentou relativamente pequena perda total de água e perda total de solo essencialmente nula, independentemente das sequências culturais, conforme também observado pelos últimos autores mencionados. Surpreendeu no estudo o sexto teste de erosão (T6), o qual, embora com a superfície do solo mais intensamente mobilizada (recém-gradeada por sobre a escarificação realizada há um mês e já tendo sofrido a ação de duas chuvas, em T4 e T5) e descoberta, resultou em perda total de água e de solo praticamente nula. Isso, talvez, possa ser explicado pela maior fragmentação dos torrões nesse teste, remanescentes da escarificação de um mês, e, em decorrência, pelo rompimento da crosta sobre eles, devido à ação da grade, fazendo com que uma maior extensão e uma melhor condição de superfície do solo estivessem nele presentes para infiltrar quase toda a água da chuva aplicada em uma hora e meia de duração do evento erosivo, praticamente eliminando a enxurrada e a erosão.

Tudo o que foi mencionado é novamente confirmado ao se analisarem os resultados obtidos nas suas formas globais, por sequências culturais e por testes de erosão (Figura 2). Assim, observou-se que a sequência cultural envolvendo teosinto foi a que apresentou menor perda total de água, diferindo significativamente das demais sequências, as quais não diferiram entre si e apresentaram valores ao redor do dobro da primeira (Figura 2a). A segunda menor perda total de solo esteve associada com a sequência cultural envolvendo teosinto (Figura 2b), entretanto sem diferir estatisticamente daquelas envolvendo milho + feijãomiúdo e milheto, ao passo que as sequências culturais envolvendo feijão-miúdo e milho + feijão-de-porco apresentaram valores várias vezes maiores do que as já referidas e estatisticamente diferentes entre si. Esses fatos, em princípio, evidenciam que a ação exercida pelas raízes das plantas que compuseram as sequências culturais avaliadas manifestou-se mais em termos de resistência conferida ao solo para que ele pudesse se contrapor melhor à desagregação de suas partículas pela ação da chuva e da enxurrada a ela associada do que na melhoria da infiltração e da movimentação da água no interior do solo.

Quanto aos testes de erosão em si, os menores valores médios de perda total de água estiveram associados ao primeiro, quarto, quinto e sexto testes (T1, T4, T5 e T6), sem diferenças significativas entre eles, com o segundo e terceiro testes (T2 e T3) apresentan- 

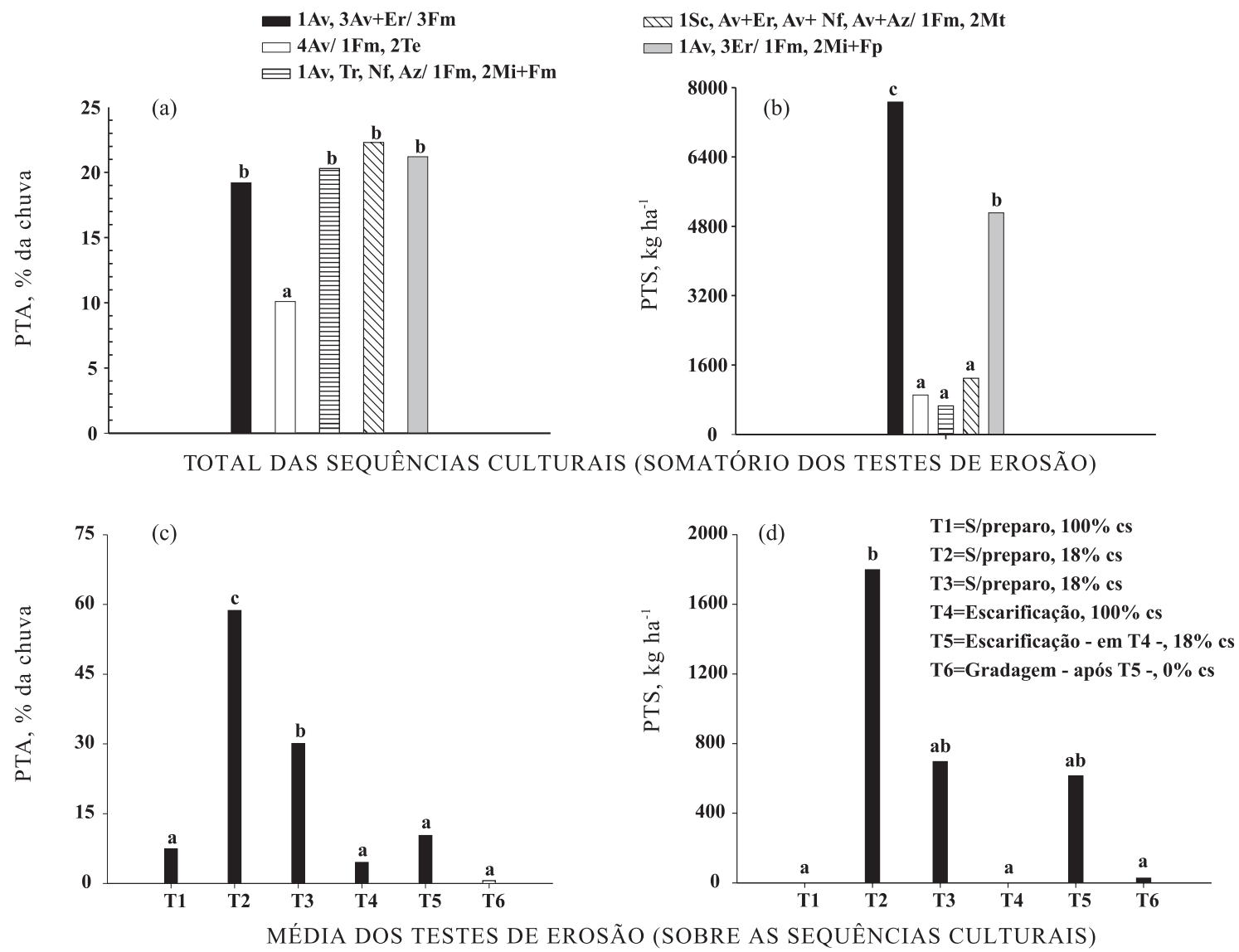

Figura 2. Perda total de água (PTA) e perda total de solo (PTS) para as sequências culturais - somatório dos testes de erosão (a e b, respectivamente), e para os testes de erosão-médias das sequências culturais (c e d, respectivamente)

do valores bem maiores, especialmente T2, e estatisticamente diferentes entre si (Figura 2c). Considerando os testes em que houve erosão (T2, T3, T5 e T6), o maior valor de perda total de solo esteve associado ao segundo teste (T2), diferindo significativamente dos demais, seguido do terceiro e quinto testes (T3 e T5), os quais não diferiram entre si e apresentaram valores em torno da metade do de T2 (Figura 2d).

De modo geral, observou-se que as diferenças nos resultados das variáveis de erosão hídrica consideradas no estudo foram maiores entre os testes de erosão do que entre as sequências culturais, evidenciando que as condições físicas externas ou superficiais do solo instantânea e mecanicamente criadas por ação programada influenciaram o processo erosivo mais do que as condições físicas internas ou subsuperficiais lenta e naturalmente criadas pela ação das raízes das plantas.

\section{CONCLUSÕES}

1. As sequências culturais e os testes de erosão influenciaram significativamente os resultados da pesquisa, com as diferenças entre eles sendo maiores nos últimos do que nas primeiras.

2. As condições físicas externas ou superficiais do solo, criadas por ação mecânica rápida, influenciaram o processo erosivo mais do que as condições físicas internas ou subsuperficiais, criadas ao natural pela ação das raízes das espécies vegetais que constituíram as sequências culturais.

3. De modo geral, todas as sequências culturais foram eficazes na restauração da estrutura do solo no período da experimentação, sobressaindo a com teosinto.

4. A sequência cultural com teosinto, no que se refere à perda de solo e água, e as com milho+feijãomiúdo e milheto, no tocante à perda de solo, foram as que melhor controlaram o processo de erosão hídrica pluvial.

5. A superfície de solo não mobilizada e com pouca cobertura por resíduo cultural foi a que mais favoreceu a enxurrada e a erosão, independentemente da presença e do tipo de crosta, especialmente quando esta última foi levemente rompida antes da aplicação da chuva. 
6. A superfície de solo inteiramente coberta por resíduo cultural - tenha sido ela não mobilizada ou recém-escarificada - controlou a enxurrada de modo eficaz e impediu totalmente a erosão.

7. A superfície de solo recém-gradeada por sobre a superfície escarificada há um mês, embora com o solo o mais mobilizado de todos e descoberto, praticamente não apresentou perdas de solo e água, contrariando o que se esperava.

\section{LITERATURA CITADA}

BADELUCCI, M.P. Infiltração de água e perdas por erosão em diferentes métodos de melhoramento da pastagem nativa. Porto Alegre, Universidade Federal do Rio Grande do Sul, 1997. 137p. (Tese de Mestrado)

BERTOL, I.; ALBUQUERQUE, J.A.; LEITE, D.; AMARAL, A.J. \& ZOLDAN JÚNIOR, W.A. Propriedades físicas do solo sob preparo convencional e semeadura direta em rotação e sucessão de culturas comparadas às do campo nativo. R. Bras. Ci. Solo, 28:155-163, 2004.

BOUMA, J. Guide to the study of water movement in soil pedons above the water table. Madison, University of Wisconsin, 1973. 194p.

BRUCE, R.R.; LANGDALE, G.W. \& DILLARD, A.L. Tillage and crop rotation effect on characteristics of a sandy surface soil. Soil Sci. Soc. Am. J., 54:1744-1747, 1990.

CAMPOS, B.C.; REINERT, D.J.; NICOLODI, R. \& CASSOL, L.C. Dinâmica da agregação induzida pelo uso de plantas de inverno para cobertura do solo. R. Bras. Ci. Solo, 23:383391, 1999.

CARVALHO, A.M. \& AMABILE, R.F. Plantas condicionadoras de solo: Interação edafoclimática, uso e manejo. In: CERRADO: Adubação verde. Planaltina, Embrapa Cerrado, 2006. p.143-170.

CASTRO, L.G.; COGO, N.P. \& VOLK, L.B.S. Alterações na rugosidade superficial do solo pelo preparo e pela chuva em solo com cessamento de cultivo, na ausência e na presença de cobertura por resíduo cultural, e sua relação com a erosão hídrica. R. Bras. Ci. Solo, 30:339-352, 2006.

COGO, N.P.; MOLDENHAUER, W.C. \& FOSTER, G.R. Effect of residue cover, tillage-induced roughness, and runoff velocity on size distribution of eroded soil aggregates. Soil Sci. Soc. Am. J., 47:1005-1008, 1983.

COGO, N.P. Effect of residue cover, tillage-induced roughness and slope length on erosion and related parameters. West Lafayette, Purdue University, 1981. 346p. (Tese de Doutorado)

DAILY, G.C.; MATSON, P.A. \& VITOUSEK, P.M. Ecosystem services supplied by soil. In: DAILY, G., ed. Natures services: Societal dependence on natural ecosystems. Washington, Island Press, 1997. p.113-132.

DANIELSON, R.E. \& SUTHERLAND, P.L. Porosity. In: BLACK, C.A., ed. Methods of soil analysis. I. Physical and mineralogical methods. Madison, American Society of Agronomy/Soil Science Society of America, 1986. p.443461.
EMPRESA BRASILEIRA DE PESQUISA AGROPECUÁRIA EMBRAPA. Centro Nacional de Pesquisa de Solos. Sistema brasileiro de classificação de solos. Rio de Janeiro, 2006. 306p.

FORSYTHE, W. Fisica de suelos: Manual de laboratório. San José, Costa Rica, IICA, 1975. 212p.

HARTWIG, R.O. \& LAFLEN, J.M. A meterstick method for measuring crop residue cover. J. Soil Water Conserv., 33:90-91, 1978.

HUDSON, N.W. Soil conservation. 3.ed. Ames, lowa State University Press, 1995. 391p.

KAY, B.D. Soil structure and organic carbon: A review. In: LAL, R.; KIMBLE, J.M.; FOLLETT, R.F. \& STEWART, B.A., eds. Soil processes and the carbon cycle. Boca Raton, CRC Press, 1998. p.169-197.

KEMPER, W.D. \& CHEPIL, W.S. Size distribution of aggregates. In: BLACK, C.A., ed. Methods of soil analysis, physical and mineralogical properties, including statistics, measurement and sampling. Madison, American Society of Agronomy, 1965. p.499-510.

KIEHL, J.E. Manual de edafologia. São Paulo, Agronômica Ceres, 1979. 262p.

LAL, R. \& GREENLAND, B.J. Soil physical properties and crop production in tropics. Chichester, J. Willey, 1979. p.7-85.

MALLORY, E.B. \& PORTER, G.A. Potato yield stability under contrasting soil man-agement strategies.Agron.J., 99:501$510,2007$.

MIELNICZUK, J. \& SCHNEIDER, P. Aspectos sócioeconômicos do manejo do solo no Sul do Brasil. In: SIMPÓSIO DE MANEJO DO SOLO E PLANTIO DIRETO NO SUL DO BRASIL; SIMPÓSIO DE CONSERVAÇÃO DE SOlOS DO PLANALTO, 3., Passo Fundo, 1983. Anais... Passo Fundo, 1984.

NORTON, L.D.; COGO, N.P. \& MOLDENHAUER, W.C. Effectiveness of mulch in controlling soil erosion. In: EL SWAIFY, S.A.; MOLDENHAUER, W.C. \& LO, A., eds. Soil erosion and conservation. Ankeny, Soil Conservation Society of America, 1985. p.598-606

NUERNBERG, N.J.; STAMMEL, J.G. \& CABEDA, M.S.V. Efeito de sucessão de culturas e tipos de adubação em características físicas de um solo da encosta basáltica sulrio-grandense. R. Bras. Ci. Solo, 10:185-190, 1986.

POCH, R.M. \& MARTINEZ-CASASNOVA, A. Degradation. In: RAFTAN, L., ed. Encyclopedia of soil science. New York, Marcel Dekker, 2002. v.1. p.260-263.

PORTELA, J.C. Restauração da estrutura do solo por sequências culturais e sua relação com a erosão hídrica. Porto Alegre, Universidade Federal do Rio Grande do Sul, 2009. 209p. (Tese de Doutorado)

RENARD, K.G.; FOSTER, G.R.; WEESIES, G.A.; McCOOL, D.K. \& YODER, D.C. Predicting soil erosion by water: A guide to conservation planning with the revised universal soil loss equation (RUSLE). Washington, U.S. Department of Agriculture, 1997. 384p. (Agriculture handbook, 703). 
RILEY, H.; POMMERESCHE, R.; ELTUN, R.; HANSEN, S. \& KORSAETH, A. Soil structure, organic matter and earthworm activity in a comparison of cropping systems with contrasting tillage, rotations, fertilizer levels and manure use. Agric. Ecosyst.Environ.,124:275-284, 2008.

SCHJONNING, P. \& CHRISTENSEN, B.T. Physical and chemical properties of a sandy loam receiving animal manure, mineral fertilizer or no fertilizer for 90 years. Europ. J. Soil Sci., 45:257-268, 1994.

SENESI, N. \& LOFFREDO, E. The chemistry of soil organic matter. In: SPARK, D.L., ed. Soil physical chemistry. Boca Raton, CRC Press, 1999. p.239-370.

SILVA, I.F. \& MIELNICZUK, J. Ação do sistema radicular de plantas na formação e estabilização de agregados do solo. R. Bras. Ci. Solo, 21:113-117, 1997.

SILVA, I.F. Formação, estabilidade e qualidade de agregados do solo afetados pelo uso agrícola. Porto Alegre, Universidade Federal do Rio Grande do Sul, 1993. 126p. (Tese de Doutorado)

SIX, J.; FELLER, C.; DENEF, K.; OGLE, S.M.; SÁ, J.C.M. \& ALBRECHT, A. Soil carbon matter, biota and aggregation in temperate and tropical soils: Effects of no-tillage. Agronomie, 22:755-775, 2002.

SPERA, S.T.; SANTOS, H.P.; FONTAENLI, R.S. \& TOMM, G.O. Efeito de sistemas de produção de grãos envolvendo pastagens sob plantio direto nos atributos físicos do solo e sua produtividade. R. Bras. Ci. Solo, 28:533-542, 2004.
STONE, L.F. \& GUIMARÃES, C.M. Influência de sistemas de rotação de culturas nos atributos físicos do solo. Santo Antonio de Goiás, Embrapa Arroz e Feijão, 2005. 15p. (Boletim de Pesquisa e Desenvolvimento)

STONE, L.F. \& SILVEIRA, P.M. Efeitos do sistema de preparo e da rotação de culturas na porosidade e densidade do solo. R. Bras. Ci. Solo, 25:395-401, 2001.

STRECK, E.V. Erosão hídrica do solo relacionada com o subfator uso anterior da terra do modelo "RUSLE". Porto Alegre, Universidade Federal do Rio Grande do Sul, 1999. 195p. (Tese de Doutorado)

SWANSON, N.P. A rotating - boom rainfall simulador. Trans. Am. Soc. Agric. Eng., 26:1738-1743, 1965.

VOLK, L.B.S. Condições físicas da camada superficial do solo resultante do seu manejo e identificadores de qualidade para redução da erosão hídrica pluvial e do escoamento superficial. Porto Alegre, Universidade Federal do Rio Grande do Sul, 2006. 68p. (Tese de Doutorado)

VOLK, L.B.S. Erosão hídrica relacionada às condições físicas de superfície e subsuperfície do solo, induzidas por formas de cultivo e de manejo dos resíduos culturais. Porto Alegre, Universidade Federal do Rio Grande do Sul, 2002. 146p. (Tese de Mestrado)

WISCHMEIER, W.H. \& SMITH, D.D. Predicting rainfall erosion losses: A guide to conservation planning. Washington, USDA, 1978. 58p. (Agricultural Handbook, 537) 